\title{
GeoGebra e Sala de Aula Invertida: uma possibilidade para a formação continuada de professores no contexto da Matemática
}

\author{
GeoGebra and Flipped Classroom: A possibility for continuing \\ teacher education in the Mathematical context
}

\author{
Celina Aparecida Almeida Pereira Abar ${ }^{1}$ \\ Renata Udvary Rodrigues ${ }^{2}$
}

\section{RESUMO}

Este artigo apresenta resultados parciais de uma pesquisa de Mestrado Acadêmico em Educação Matemática que teve como objetivo principal verificar se uma formação continuada, para professores do Ensino Fundamental - Anos Iniciais, sobre Geometria Plana e Espacial, com a utilização de tecnologia digital e no modelo da Sala de Aula Invertida - SAI, pode criar condições para a autonomia do professor no que diz respeito à atualização de seus conhecimentos, bem como o aprimoramento de sua prática docente. O trabalho buscou investigar qual é a percepção dos professores quanto à utilização de recursos tecnológicos, incluindo o software GeoGebra como proposta de aprimoramento de seus conhecimentos em Geometria. A formação denominada "Geometria e Ensino Híbrido... Você já ouviu falar?" abordou aspectos teóricos e metodológicos com a utilização de tecnologias digitais na busca do aperfeiçoamento profissional desses professores e evidenciou a viabilidade de sua continuidade, com a adoção de outros modelos de Ensino Híbrido, podendo ser reestruturada para outros professores e conteúdos, o que, certamente, trará contribuições significativas para estudos na área.

Palavras-chave: Formação de Professores Pedagogos; Ensino Híbrido, Sala de Aula Invertida, Tecnologias e Educação Matemática; GeoGebra.

1. Professora do Programa de Estudos Pós-graduados em Educação Matemática da PUC-SP. Email: abarcaap@gmail.com

2. Doutoranda do Programa de Estudos Pós-graduados em Educação Matemática da PUC-SP. Email: renataudvary@gmail.com. 


\section{ABSTRACT}

This paper presents partial results of a research of the Academic Master in Mathematical Education, that had as main objective to verify if a continuous formation for teachers of the Elementary School, in Flat and Spatial Geometry, with the use of digital technology and in the flipped classroom model can create conditions for teacher autonomy with regard to updating their knowledge, as well as improving their teaching practice. The work sought to investigate the teachers' perception regarding the use of technological resources, including GeoGebra software as a proposal to improve their knowledge in Geometry. The formation called "Geometry and Blended Learning... Have you heard?" addressed theoretical and methodological aspects with the use of digital technologies in the pursuit of professional improvement of these teachers and evidenced the viability of their continuity, with the adoption of other models of Blended Learning, which can be restructured for other teachers and other contents which certainly will make significant contributions.

Keywords: Teacher Education, Blended Learning, Flipped Classroom, Technologies and Mathematical Education, GeoGebra.

\section{Introdução}

Neste artigo são apresentados resultados parciais de uma pesquisa de Mestrado Acadêmico, que teve como objetivo desenvolver uma proposta de formação continuada para professores do Ensino Fundamental - Anos Iniciais, no contexto da Geometria Plana e Espacial com base no modelo da Sala de Aula Invertida e uso de tecnologias digitais como Moodle e GeoGebra.

A questão principal foi verificar se a proposta de uma formação continuada para professores do Ensino Fundamental - Anos Iniciais poderia criar condições de atualização de seus conhecimentos e aprimoramento de sua prática docente com o uso de tecnologia, por meio de um modelo de Ensino Híbrido. Conjecturou-se como uma maneira de apresentar possibilidades para que a inclusão digital pudesse ser feita de forma a valorizar as tecnologias digitais e que pudessem trazer para a educação uma expansão ou mudança do que se entende tradicionalmente por sala de aula.

Apresentamos um breve panorama do Ensino de Geometria nas escolas básicas, a formação específica em Matemática dos professores dos anos iniciais e, consequentemente, a importância das formações continuadas. Exibimos elementos do modelo da Sala de Aula Invertida, 
SAI, adotado e as possíveis contribuições que a tecnologia digital na formação continuada de professores pode trazer para o aprimoramento da prática pedagógica.

Como aporte teórico a abordagem do Conhecimento Tecnológico, Pedagógico e do Conteúdo - TPCK, que segundo MISHRA e KOEHLER (2006) vai além de capacitar o professor nessas três bases de conhecimento isoladas, ressaltando que as novas habilidades necessárias aos professores se encontram nas intersecções entre elas. Essa teoria é uma evolução da proposta de SHULMAN (1987), que argumenta sobre a importância do conhecimento pedagógico do professor em formação inicial ou continuada e a teoria TPCK acrescenta a esse primeiro modelo o conhecimento tecnológico.

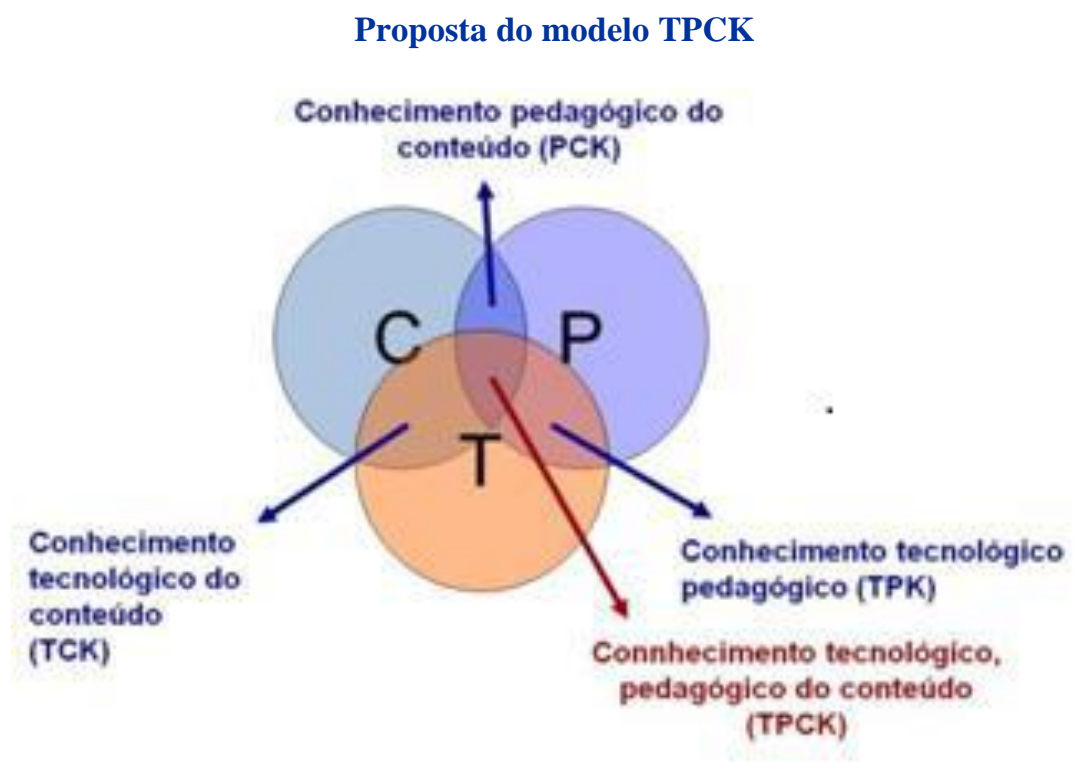

Fonte: Adaptado de MISHRA \& KOEHLER, 2006.

A pesquisa foi de caráter qualitativo e utilizou-se da metodologia do Design Research ou Design Experiments (COLLINS, A. JOSEPH, D, BIELACZYC, K., 2014) que pode ser entendida como um progressivo aprimoramento da investigação, que consiste em aplicar uma primeira versão e que seja possível verificar e analisar como ela acontece e, subsequentemente, para que seja revista de maneira 
constante com base nas experiências colhidas e avaliadas, até que os obstáculos surgidos no processo sejam minimizados, incluindo a abordagem de teoria, perguntas e questões. É um recurso para que a pesquisa se apresente como eficaz e, desse modo, atinja a dupla meta de aprimoramento, tanto na teoria como na prática.

Completando o artigo, apresentamos o desenvolvimento da pesquisa com professores dos anos iniciais do Ensino Fundamental e finalizamos apresentando alguns resultados obtidos e as considerações finais.

\section{Panorama do Ensino de Geometria nas escolas básicas}

NACARATO e SANTOS (2014) apresentam um breve histórico sobre o ensino da Geometria Plana na Educação Básica, quando afirmam que o ensino de Geometria no Brasil passou por várias fases. Até 1960, ele se desenvolvia com base em estudos de Euclides, ou seja, pelo método dedutivo axiomático. Entre 1970 e 1980, por influência do Movimento da Matemática Moderna, o ensino tinha ênfase, principalmente, em estruturas e na linguagem matemática, dificultando a compreensão dos conceitos de Geometria.

Segundo PEREZ (1991), o ensino de Geometria passou a ser difícil para os professores que, perdidos no meio das controvérsias que giravam em torno do método axiomático euclidiano sobre as demonstrações de alguns teoremas e, sobretudo, sem entenderem o que a Álgebra Linear tinha a ver com o ensino da Geometria. Assim, o tema foi colocado como conteúdo para o último plano, aspecto que de certa forma foi facilitado pelo fato dos livros didáticos, existentes naquela época, trazerem os conteúdos geométricos nos capítulos finais. Isso, de certa forma, contribuiu para que o ensino desse conteúdo se tornasse bastante insatisfatório, provocando o seu abandono pela escola.

Contudo, indo ao encontro ao senso comum dos docentes, PEREZ (1991) problematiza que:

O professor precisa refletir sobre a concepção de escola, como instituição que transmite conhecimentos e como local que ajuda o aluno a desenvolver o seu potencial intelectual, que o ensina a pensar, que o ajuda a descobrir caminhos para efetuar transformações na sociedade em que vive. (PEREZ, 1991, p.25). 
Afirmando ainda que:

O ensino por repetição pouco ajuda o aluno a desenvolver o seu potencial intelectual, contribuindo assim com o empobrecimento da Matemática pelo fato de não contar com a participação do aluno na construção do conteúdo daquele conhecimento. (PEREZ, 1991, p.26).

PAVANELLO (1993) ainda destaca que:

A maioria dos alunos do $1^{\circ}$ grau deixa de aprender geometria, pois os professores das series iniciais limitam-se, em geral, a trabalhar somente o conteúdo algébrico. $\mathrm{O}$ estudo de Geometria passa a ser feito, quando não é eliminado, apenas no $2^{\circ}$ grau com o agravante de que os alunos apresentam uma dificuldade ainda maior em lidar com as figuras geométricas e sua representação, porque o Desenho Geométrico é substituído, nos dois graus de ensino, pela Educação Artística. (PAVANELLO, 1993, p.13).

A autora indica ainda que o abandono do ensino de Geometria pode ser explicado devido ao contexto histórico político da época e que, apesar do abandono da Geometria no ensino ser uma tendência geral, era um problema mais evidente no ensino público, que foi agravado após a promulgação da Lei 5692/71 que permitiu ao professor elaborar seu programa de ensino de acordo com a necessidade de seus alunos. Tal liberdade, concedida por esta Lei, possibilitou aos professores de Matemática, sentindo-se inseguros para trabalhar com a Geometria, a não inclusão em sua programação ou que a colocassem no final do ano letivo, usando a falta de tempo como pretexto para não abordá-la.

Os Parâmetros Curriculares Nacionais do Ciclo I - PCN (BRASIL, 2001), destacam a importância dos conceitos geométricos estarem presentes nos currículos de Matemática, proporcionando ao aluno o desenvolvimento de um pensamento, ressaltado nos PCN (BRASIL, 2001, p.55) como "o de compreender, descrever e representar de forma organizada o mundo em que vive", além da Geometria ser um tema de interesse dos alunos, podendo ser trabalhada com situações-problema, contribuindo para a aprendizagem de outros temas, estimulando a criança a observar e perceber as semelhanças e diferenças, bem como identificar regularidades. E encerram as considerações didáticas afirmando que: "o uso de alguns softwares disponiveis também é uma forma de levar o aluno a raciocinar geometricamente". 
Segundo a BNCC (BRASIL, 2017), a Geometria envolve o estudo de um amplo conjunto de conceitos e procedimentos necessários para resolver problemas do mundo físico e de diferentes áreas do conhecimento. As ideias matemáticas fundamentais associadas a essa temática "Geometria" são, principalmente, construção, representação e interdependência.

PCN (BRASIL, 2001) e BNCC (BRASIL, 2017), portanto, compartilham da importância do Ensino da Geometria no Ensino Fundamental - Anos Iniciais, inclusive com o uso de tecnologias. Com isso, a importância de o professor ter domínio não só do conteúdo a ser ensinado, como também de estratégias pedagógicas inovadoras e eficientes, justifica a formação continuada dos profissionais como será ressaltado no próximo item.

\section{Um panorama da formação Matemática de professores dos anos iniciais do Ensino Fundamental}

Embora as noções de Matemática sejam recorrentes em nosso cotidiano e, desde sempre, introduzidas na rotina escolar das crianças, a Matemática só é apresentada às crianças como uma disciplina do currículo escolar nos anos iniciais do Ensino Fundamental.

A formação de professores que atuam nas séries iniciais do Ensino Fundamental ocorre nos cursos de Pedagogia que, atualmente, de acordo com a $2^{\circ}$ Resolução CNE/CP n 001 de 2006 instituída nas Diretrizes Curriculares Nacionais (BRASIL, 2006), destina-se à Formação inicial para o exercício na Educação Infantil e nos anos iniciais do Ensino Fundamental, nos cursos de Ensino Médio, na Modalidade Normal e em cursos de Educação Profissional na área de serviços e apoio escolar, bem como em outras áreas nas quais sejam previstos conhecimentos pedagógicos. Esses profissionais irão lecionar diferentes disciplinas e, para tanto, devem ter o domínio e a didática dos conteúdos relacionados a cada uma.

Também de acordo com a Resolução CNE/CP n ${ }^{\circ} 1$ de 2006, o aluno de Pedagogia deverá articular a "decodificação e utilização de códigos de diferentes linguagens utilizadas por crianças, além do trabalho didático dos conteúdos pertinentes aos primeiros anos de escolarização, relativos à Língua Portuguesa, Matemática, Ciências, História e Geografia, Artes e Educação Física” (p. 21). 
Porém, com relação à formação de Matemática nos cursos de Pedagogia, Curi (2005), em sua pesquisa, aponta que noventa por cento $(90 \%)$ dos cursos de pedagogia priorizam as questões metodológicas como essenciais à formação desse profissional, contudo, as disciplinas que abordam tais questões contam com uma carga horária bastante reduzida.

LIBÂNEO (2013), ao analisar os currículos do curso de Pedagogia no que se refere à disciplina de Matemática, mostra que a frágil preparação desses conteúdos, no que diz respeito ao seu aprofundamento teórico, na didática para transmissão das noções e dos elementos da ciência, incluindo o conhecimento de tecnologias, principalmente as digitais, no desenvolvimento de estratégias, poderiam garantir melhor aprendizado na atualidade que está fragilizado, em parte, em função da formação do professor.

NACARATO, MENGALI e PASSOS (2017) destacam as reformas curriculares que ocorreram nos últimos trinta anos na educação brasileira e, por meio de uma retrospectiva sobre esse movimento, as autoras entendem que futuras professoras polivalentes têm tido poucas oportunidades para uma formação matemática que possa fazer frente às atuais exigências da sociedade e das reformas curriculares desenvolvidas. Quando ocorre tal oportunidade na formação inicial, essa vem se pautando em aspectos metodológicos.

Segundo MELLO (2001, p.156): Ninguém promove aprendizagem de conteúdos que não domina nem a constituição de significados que não possui ou a autonomia que não teve oportunidade de construir.

Deste modo, ensinar Matemática nos anos iniciais é uma tarefa especial e desafiadora para boa parte dos professores licenciados em Pedagogia, visto que as disciplinas relacionadas ao conhecimento da Matemática podem não os preparar suficientemente para a docência dos conteúdos determinados pelo plano pedagógico.

$\mathrm{Na}$ tentativa de amenizar os aspectos acima expostos, a pesquisa desenvolvida ofereceu uma formação continuada a professores do Ensino Fundamental - Anos Iniciais, com a utilização de um dos modelos de Ensino Híbrido: a Sala de Aula Invertida, apresentado a seguir. 


\section{Ensino Híbrido: modelo da Sala de Aula Invertida}

O Modelo da Sala de Aula Invertida, SAI, pode ser entendido como uma inversão do que é feito tradicionalmente em casa, é executado em sala de aula e vice-versa. Esse modelo pode trazer novos horizontes para a formação de professores, pois permite que aqueles que apresentam dificuldades para se inserirem nas oportunidades de formação, atualizem-se de acordo com seu tempo e espaço. É um modelo de Ensino Híbrido ou Blended Learning que, por sua vez, está inserido nas Metodologias Ativas.

Essas metodologias são estratégias de ensino centradas na participação efetiva dos participantes que, de acordo com LOPES et al (2003), permitem criar um ambiente de motivação para engajar os sujeitos nas atividades; possibilita a reflexão como forma de construção dos conceitos; estimula a cooperação entre os participantes; desenvolve a autonomia na busca de informação e a capacidade de investigação.

TORI et al (2009) refere-se ao Ensino Híbrido como:

Dois ambientes de aprendizagem que historicamente se desenvolveram de maneira separada, a tradicional sala de aula presencial e o moderno Ambiente Virtual de Aprendizagem, e que vêm se descobrindo mutuamente complementares. O resultado desse encontro são cursos híbridos que procuram aproveitar o que há de vantajoso em cada modalidade, considerando contexto, custo, adequação pedagógica, objetivos educacionais e perfis dos alunos (TORI, R; LITTO, F. M. LITTO; FORMIGA, M, 2009, p.121).

Segundo BERGMANN e SAMS (2016), todo professor que optar pela inversão da sala de aula terá maneiras distintas de colocá-la em prática; eles ponderaram que:

[...] quando começamos a aplicar a inversão de salas de aula, logo percebemos que havíamos nos deparado com um sistema que efetivamente capacitaria os professores a personalizar o ensino para cada aluno - o objetivo dos educadores desde os primórdios do conceito de aprendizagem individualizada. Ao apresentarmos nosso modelo de Sala de Sula Invertida a educadores de todo o mundo, muitos disseram: "Esse método é replicável, escalável, personalizável e facilmente ajustável às idiossincrasias de cada professor”. (BERGMANN; SAMS, 2016, p.6). 
Com isso, obtém-se uma integração entre atividades realizadas em sala de aula e atividades online no Ambiente Virtual de Aprendizagem - AVA, com a ressalva de que o sujeito controla seu lugar, tempo e ritmo de sua aprendizagem.

No desenvolvimento da pesquisa foi utilizada a plataforma digital Moodle que atendeu aos requisitos necessários com os recursos de que dispõe e, ao mesmo tempo, apresenta aos professores uma possibilidade de outros cursos de formação continuada disponíveis em diversas instituições.

\section{Tecnologias Digitais}

A sala de aula vive, hodiernamente, uma fase de aproveitamento e descobrimento de novos recursos tecnológicos. Entretanto, para que isso possa acontecer de maneira satisfatória e que resulte em bons processos didáticos, não basta apenas equipar as salas de aula com máquinas; é preciso preparar os professores com relação ao conhecimento matemático e ambientá-los às tecnologias disponíveis. Contudo, existe ainda alguma resistência ou certa dificuldade por parte dos educadores em incorporar a prática de recursos tecnológicos em sua rotina docente.

A atual geração já nasceu em tempos em que há farta disponibilidade de tecnologias diversas; muitos possuem intimidade com interfaces digitais, porém, o grande desafio está em direcionar, com base em boas estratégias didáticas, o potencial de manuseio dessas habilidades tecnológicas dos jovens para a construção do saber, pois tanto na Matemática como em qualquer outra disciplina, o envolvimento do aluno é uma condição fundamental para a aprendizagem. O aluno tem condições de aprender quando mobiliza os seus recursos cognitivos e afetivos, com vista a atingir um objetivo do sucesso na aquisição do conhecimento.

Para que se busque o sucesso na aquisição do conhecimento Matemático, a temática tem que se tornar atrativa aos alunos. É necessário incentivar o pensamento crítico, o raciocínio lógico, colocálos em situações mais próximas da realidade de modo a instigar a curiosidade. Urge trazer o ensino da Matemática para o mundo prático e atual, inserindo-o na era da tecnologia digital, propiciando ao aluno uma aprendizagem investigativa. 
Vale ressaltar então que:

Nessa perspectiva, a incorporação das TIC se dá no sentido de abrir possibilidades para fazer, pensar e conviver, que não poderiam ser pensadas sem a presença dessas tecnologias, assim como nas investigações Matemáticas, no nosso caso específico a Geometria, onde contribuem para uma compreensão de fatos e relações geométricas que vão muito além da simples memorização e utilização de técnicas, contribuem para perceber aspectos essenciais da atividade matemática, contribuem para concretizar a relação entre situações da realidade e situações matemáticas, desenvolvem capacidades, tais como a visualização espacial, desenvolvem a habilidade de usar diferentes formas de representação, contribuem para evidenciar conexões matemáticas e ainda contribuem em ilustrar aspectos interessantes da história e da Matemática. (PONTE, J. P.; BROCARDO, J.; OLIVEIRA, H, 2009, p.71).

Além disso, segundo BONILLA e PICANÇO (2005), o uso das TIC introduz um novo sistema simbólico para ser processado, reorganiza a visão de mundo de seus usuários, modifica hábitos cotidianos, valores e crenças, constituindo-se em elementos estruturantes das relações sociais; os processos evidenciam um movimento ininterrupto de construção de cultura e conhecimento.

Embora possa passar aos alunos a impressão de que o recurso seja somente lúdico, ao trabalhar com as tecnologias digitais no ciclo de alfabetização, o professor deve ter cuidado para que sua utilização não seja entendida como um mero passatempo.

Para isso, a seleção de software e o planejamento da aula são fundamentais para que a criança consiga estabelecer relações entre as situações vivenciadas na sala de aula e as situações vivenciadas com o uso de tecnologias digitais, cruzando os caminhos de conhecimento e acolhendo as noções científicas a contento.

Portanto, segundo PIMENTEL (2007), atrelada à mudança de paradigma está a compreensão de que o papel do professor na atualidade é o de estimular os alunos a aprenderem a buscar e selecionar as fontes de informação disponíveis para a construção do conhecimento, analisando-as e reelaborando-as.

E, mais importante do que o professor dominar as técnicas, o fato de estar apto a construir o percurso com os estudantes, os quais, muitas 
vezes, já se apropriaram das tecnologias sem saberem utilizá-las em seu cotidiano educacional, é fundamental.

$\mathrm{Na}$ pesquisa foram disponibilizados vídeos e textos teóricos no Moodle, que eram norteadores das atividades propostas, fazendo uso do GeoGebra, um software livre que permite uma exploração dinâmica de conteúdos de matemática e disponibilizado em cada tópico estudado, configurando, assim, a proposta de envolvimento dos professores com ferramentas digitais.

No próximo item apresentamos a estrutura e o desenvolvimento da formação continuada com professores do Ensino Fundamental I.

\section{A estrutura e o desenvolvimento da formação dos professores}

A formação foi realizada com professores pedagogos de escolas de Ensino Fundamental - Anos Iniciais $\left(1^{\circ}\right.$ ao $5^{\circ}$ ano $)$ da rede pública municipal de São Paulo, envolvendo o ensino presencial e online, no ambiente Moodle.

O desenvolvimento do projeto se deu por meio de módulos e tópicos, conforme foram preliminarmente estabelecidos: o objetivo do módulo, o conteúdo matemático presente nele, os recursos tecnológicos pertinentes e os espaços físicos a serem utilizados, segundo aspectos da proposta da SAI e o modelo adotado neste estudo.

No início de cada módulo, inseriu-se uma trilha de aprendizagem, exemplo apresentado abaixo, a fim de auxiliar o professor na organização do seu tempo e de suas atividades. 
Figura 1. Exemplo de trilha de aprendizagem

\section{Tópico 1 - Explorando Triângulos}

TRILHA DE APRENDIZAGEM DO TÓPICO 1

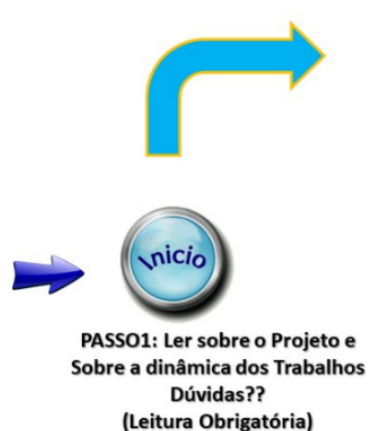

(Leitura Obrigatória)

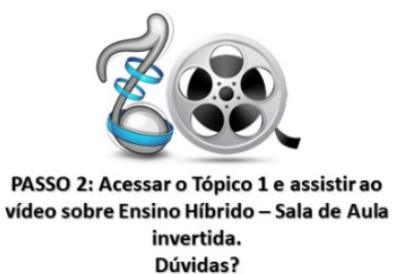

Dúvidas?

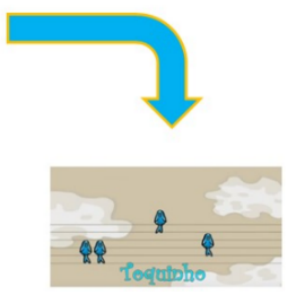

PASSO 3: Ir para Passos Iniciais

ver o vídeo, responder as perguntas e em seguida ler 0

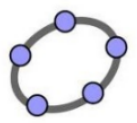

PASSO 5: Dúvidas?

PASSO 4: Assistir ao vídeo Tutorial do GeoGebra Resolver as atividades - Parte 1 - que serão propostas

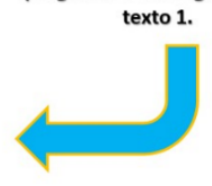

Fonte: criação das autoras

O grande norte das trilhas de aprendizagem pode ser entendido como um conjunto integrado e sistemático de ações de desenvolvimento, as quais recorrem a múltiplas formas de aprendizagem para dar suporte ao aluno, já que ele é o próprio protagonista de sua formação e qualificação. Alguém que almeje por oportunidades de capacitação e necessidades de aperfeiçoamento poderá criar seu mapa de aprendizagem, o seu itinerário formativo e caminhará por sua própria trilha.

Foram previstas 9 horas presenciais, divididas em três encontros de 3 horas cada, com intervalos de 15 dias entre eles e 11 horas à distância, que foram divididas entre os encontros presenciais.

No Moodle, foram disponibilizados vídeos e textos teóricos norteadores das atividades propostas para os professores, fazendo uso do GeoGebra sobre cada conteúdo estudado. 
Os conteúdos trabalhados na formação foram distribuídos como mostra o quadro a seguir:

Quadro 1. Estrutura dos Módulos

\begin{tabular}{|c|c|c|}
\hline Título dos Módulos & Horas & Estrutura dos Módulos \\
\hline $\begin{array}{l}\text { Módulo 0- } \\
\text { Presencial - } \\
\text { Apresentação do } \\
\text { Projeto, Moodle e } \\
\text { GeoGebra. } \\
\end{array}$ & $\begin{array}{l}1 \text { hora e } 30 \\
\text { minutos }\end{array}$ & $\begin{array}{l}\text { Apresentam-se a estrutura e a dinâmica da } \\
\text { formação, a plataforma Moodle, um vídeo } \\
\text { sobre o que é o Ensino Híbrido - Sala de } \\
\text { Aula Invertida e um vídeo tutorial sobre o } \\
\text { GeoGebra. }\end{array}$ \\
\hline $\begin{array}{l}\text { Módulo 1- } \\
\text { Presencial - } \\
\text { Explorando } \\
\text { Triângulos. }\end{array}$ & $\begin{array}{l}1 \text { hora e } 30 \\
\text { minutos }\end{array}$ & $\begin{array}{l}\text { Ainda no primeiro encontro presencial, mas } \\
\text { em ambiente Moodle, as atividades } \\
\text { realizadas tiveram como objeto de estudo os } \\
\text { Triângulos, com textos de apoio e uso do } \\
\text { GeoGebra. } \\
\text { Apresentou-se o vídeo da música Aquarela, } \\
\text { de Toquinho, e uma atividade relacionada a } \\
\text { ela. } \\
\text { Realizou-se uma pesquisa pessoal, com o } \\
\text { objetivo de verificar quais motivos levaram } \\
\text { os professores a participarem da formação } \\
\text { proposta e quais são as expectativas com } \\
\text { relação ao aprimoramento profissional. }\end{array}$ \\
\hline $\begin{array}{l}\text { Módulo } 2-\text { Online - } \\
\text { Explorando } \\
\text { Polígonos- } \\
\text { Utilizando o Moodle. }\end{array}$ & $\begin{array}{c}2 \text { horas e } 45 \\
\text { minutos }\end{array}$ & $\begin{array}{l}\text { Textos de apoio e atividades no GeoGebra } \\
\text { sobre Polígonos. Fórum de discussão sobre } \\
\text { a metodologia de estudo e a otimização do } \\
\text { tempo de dedicação, além do fórum de } \\
\text { dúvidas. }\end{array}$ \\
\hline $\begin{array}{l}\text { Módulo 3-Online- } \\
\text { Explorando Círculos } \\
\text { e Circunferências - } \\
\text { Utilizando o Moodle. }\end{array}$ & $\begin{array}{c}2 \text { horas e } 45 \\
\text { minutos }\end{array}$ & $\begin{array}{l}\text { Textos de apoio e atividades no GeoGebra } \\
\text { sobre Círculos e Circunferência. Texto e } \\
\text { fórum sobre o Modelo Van Hiele do } \\
\text { Desenvolvimento do Pensamento } \\
\text { Geométrico, além do fórum de dúvidas. }\end{array}$ \\
\hline $\begin{array}{l}\text { Módulo 4- } \\
\text { Presencial - } \\
\text { Esclarecendo } \\
\text { dúvidas. }\end{array}$ & 3 horas & $\begin{array}{l}\text { Atividades escritas sobre Triângulos, } \\
\text { Polígonos, Círculos e Circunferências, além } \\
\text { do espaço para discussão sobre todos os } \\
\text { conteúdos disponibilizados nos Tópicos } \\
\text { anteriores. Atividade online sobre } \\
\text { quadriláteros. Tutorial sobre o GeoGebra } \\
\text { 3D. }\end{array}$ \\
\hline $\begin{array}{l}\text { Módulo } 5 \text { - Online - } \\
\quad \text { Explorando } \\
\text { Poliedros - } \\
\text { Utilizando o Moodle. }\end{array}$ & $\begin{array}{c}2 \text { horas e } 45 \\
\text { minutos }\end{array}$ & $\begin{array}{l}\text { Textos de apoio, fórum sobre o texto de } \\
\text { apoio; atividades no GeoGebra sobre } \\
\text { Poliedros, cujo arquivo era anexado no } \\
\text { Moodle pelo participante e fórum de } \\
\text { dúvidas. }\end{array}$ \\
\hline $\begin{array}{l}\text { Módulo } 6 \text { - Online - } \\
\text { Explorando } \\
\text { poliedros e Sólidos }\end{array}$ & $\begin{array}{c}2 \text { horas e } 45 \\
\text { minutos }\end{array}$ & $\begin{array}{l}\text { Textos de apoio com respectivas discussões } \\
\text { em fórum; atividades no GeoGebra sobre } \\
\text { Poliedros e Sólidos de Revolução, com } \\
\text { fórum de dúvidas. }\end{array}$ \\
\hline
\end{tabular}




\begin{tabular}{|c|c|c|}
\hline $\begin{array}{c}\text { de Revolução - } \\
\text { Utilizando o Moodle. }\end{array}$ & & $\begin{array}{l}\text { Questionário de perfil para caracterização } \\
\text { dos sujeitos. }\end{array}$ \\
\hline $\begin{array}{c}\text { Módulo 7 - } \\
\text { Presencial - } \\
\text { Esclarecendo } \\
\text { dúvidas. }\end{array}$ & 3 horas & $\begin{array}{l}\text { Atividades escritas sobre Poliedros e } \\
\text { Sólidos de Revolução, além do espaço para } \\
\text { discussão sobre os tópicos cinco e seis. } \\
\text { Apresentação de um vídeo, contendo } \\
\text { entrevista com Ubiratan D’Ambrósio sobre } \\
\text { Geometria. Consultas a sugestões de uso de } \\
\text { material online do GeoGebra. Propôs-se a } \\
\text { elaboração de um plano de aula e o } \\
\text { preenchimento de um questionário final, } \\
\text { opinando sobre a formação oferecida e } \\
\text { propondo possíveis sugestões. }\end{array}$ \\
\hline
\end{tabular}

Os encontros presenciais ocorreram no Laboratório de Informática da Diretoria de Ensino DRE de São Miguel Paulista, onde foram discutidos, além das atividades presenciais sugeridas, os textos indicados para leitura online sobre metodologias e estratégias para a elaboração, experimentação e avaliação de situações de ensino e de aprendizagem da Geometria com o GeoGebra e, no âmbito de atividades de sala de aula, foi solicitado, no último módulo, a elaboração de um plano de aula com o uso do GeoGebra.

Neste projeto, o GeoGebra foi explorado com suas ferramentas básicas, as quais permitem a apresentação de conteúdos da Geometria para os anos iniciais do Ensino Fundamental - Anos Iniciais, de modo atraente e dinâmico.

A dinâmica do trabalho foi orientada pela participação ativa dos professores, tanto nas atividades práticas online, quanto nos encontros presenciais.

Procurou-se estimular a associação entre prática e teoria, bem como a manipulação e análise de situações-problema. Nas sessões de trabalho online, os participantes tiveram a oportunidade de aprender e aprofundar as suas competências com a utilização do GeoGebra.

Nas atividades práticas - e em uma primeira fase - foram abordadas as ferramentas, os comandos e as interfaces necessárias a cada momento. Seguidamente, houve um trabalho capacitando os professores para a criação de aplicações do GeoGebra em outras áreas.

Em uma fase seguinte, houve uma discussão sobre as atividades propostas, focando-se nas implicações conceituais, teóricas e 
metodológicas destas tarefas do ponto de vista do ensino e da aprendizagem da Matemática.

Discutiram-se, ainda, as implicações de algumas atividades no campo da investigação educacional, bem como na pesquisa Matemática, colocando-se em evidência as potencialidades do GeoGebra na criação de novo conhecimento científico.

Os instrumentos de coleta de dados utilizados foram: questionários, protocolos de professores, observações da pesquisadora nos encontros presenciais e os feedbacks nos fóruns na plataforma Moodle das atividades propostas, tanto das leituras dos textos, quanto dos vídeos disponibilizados, e as construções solicitadas durante as atividades desenvolvidas com o GeoGebra.

O primeiro questionário usado na coleta de dados foi uma Pesquisa Pessoal realizada por meio de um questionário aberto, que tinha como objetivo principal verificar quais os motivos que levaram os professores a participar da formação proposta e as suas expectativas com relação ao seu aprimoramento profissional.

O segundo questionário utilizado foi o de formato misto, denominado Questionário de Perfil que teve como objetivo a caracterização dos sujeitos com o intuito de conhecer um pouco sobre os participantes da formação. Com relação à Geometria, as informações solicitadas foram: quais conteúdos foram ensinados durante seu período escolar; quais conhecimentos sobre os documentos oficiais relativos ao ensino da Geometria; o que ensinar sobre Geometria no Ensino Fundamental - Anos Iniciais; que conhecimentos detêm sobre tecnologias; quais são os recursos didáticos utilizados em suas aulas; quais colocações faria sobre sua prática e quais são as satisfações e as frustrações na vida profissional.

O terceiro e último questionário, nesse caso um questionário aberto, foi realizado no terceiro encontro presencial, com o objetivo de conhecer a opinião dos participantes com relação a todo o processo da formação. As perguntas envolveram temas sobre: Sala de Aula Invertida, GeoGebra e Geometria e tinham o objetivo de verificar se houve alguma compreensão, por parte dos professores, sobre o modelo da Sala de Aula Invertida usada na formação; se os conteúdos de Geometria selecionados foram adequados e como os participantes se relacionaram com o uso da tecnologia digital, em especial o GeoGebra. A última 
pergunta solicitava aos professores sugestões para o aprimoramento da oficina.

Alguns fóruns disponibilizados no Moodle também tinham como objetivo abrir um canal de comunicação com a formadora, para que os participantes pudessem esclarecer possíveis dúvidas, pedir orientações, opinar sobre alguma atividade, além de relatarem sua compreensão sobre os textos de apoio.

Outro instrumento utilizado para a coleta de dados foi a análise das atividades realizadas pelos professores de cada atividade proposta.

Além disso, houve também as observações nos encontros presenciais que, segundo RIBEIRO (2005, p.32) tem a finalidade de diagnosticar as dificuldades dos professores em relação à realização das atividades e acompanhar o seu desenvolvimento no decorrer da oficina proposta.

Alguns resultados serão apresentados a seguir.

\section{Resultados Parciais}

Houve, inicialmente, vinte e nove professores inscritos e, no entanto, somente catorze tiveram participação efetiva em todo o processo. A maioria está entre 30 e 40 anos, trabalha entre 21 e 40 horas semanais, o que pode dificultar a participação em cursos de formação continuada. Não possuem curso de pós-graduação, mas a maioria já frequentou cursos de capacitação, mas não em conteúdo específico de matemática ou em Geometria e, em sua formação, tiveram pouco acesso a esse conteúdo. Segundo eles, as maiores dificuldades em ensinar Geometria no Ensino Fundamental I estão, majoritariamente, relacionadas à falta de formação inicial e continuada adequadas que poderiam proporcionar uma evolução profissional por parte do docente. O que aprenderam foi superficial ou mesmo o básico, de forma tradicional, somente com explanação de conceitos, teorias, sem relação com atividades práticas.

Com relação ao software GeoGebra utilizado como ferramenta tecnológica poucos o conheciam. Foi possível observar, mesmo considerando as dificuldades surgidas em função do desconhecido, que os professores tiveram a oportunidade de perceber as vantagens em 
utilizar um software de Geometria Dinâmica. Empenharam-se, pesquisaram, perguntaram, participando efetivamente da proposta da formação por meio da Sala de Aula Invertida.

Os professores perceberam o software GeoGebra como um recurso tecnológico útil e funcional, que pode auxiliar nas construções geométricas, possibilitando a visualização e exploração de figuras e de suas propriedades, as quais dificilmente conseguiriam perceber usando livros didáticos e os materiais concretos, normalmente utilizados em sala de aula, principalmente em se tratando da Geometria Espacial.

Afirmam ainda que o modelo SAI pode possibilitar e favorecer novas aprendizagens, a partir do momento em que incentiva a pesquisa antecipada do objeto de estudo para posterior discussão, facilitando, com isso, o dia a dia do professor, que deseja se capacitar para melhor atuar em sua atividade profissional, devido à disponibilidade de leituras e pesquisas em qualquer hora e lugar.

Entenderam também que o docente não é mais visto como centralizador do saber, mas como um mediador na aprendizagem, fazendo o aluno ser protagonista de seu processo cognitivo, visto que as aulas são mais participativas, despertando a curiosidade docente e discente, tornando o novo conhecimento mais interessante e, por isso, mais significativo.

Outro aspecto notado pelos professores participantes foi que, usando o modelo de SAI, é possível ter mais tempo em sala de aula para atender aos alunos de forma diferenciada, de acordo com cada dificuldade.

No entanto, perceberam que não é simples fazer essa inversão. Segundo os participantes, esse modelo tem um papel duplamente necessário de preparo, exigindo organização, leitura e preparação do professor em relação ao assunto, ou seja, é inevitável que, para que esse modelo tenha o resultado esperado, aconteça uma mudança de cultura do papel, tanto do professor quanto do aluno.

Pode-se afirmar que o modelo adotado nessa pesquisa pode ser promissor no sentido de favorecer, facilitar e promover $\mathrm{o}$ aperfeiçoamento dos conhecimentos dos professores para melhor prática profissional. 


\section{Considerações Finais}

O objetivo específico deste trabalho foi investigar se o modelo com base em aspectos da "Sala de Aula Invertida", envolvendo o ensino presencial e o online, em Ambiente Moodle, bem como as estratégias utilizadas, criou condições favoráveis ao processo de ensino e aprendizagem de alguns conteúdos de Geometria.

Para tanto, foi desenvolvida a prática de um projeto de formação continuada em Geometria, a qual procurou capacitar pedagogos que lecionam no Ensino Fundamental - Anos Iniciais, de escolas da prefeitura de São Paulo, da Diretoria de Ensino DRE de São Miguel Paulista. Utilizou-se o modelo SAI em um Ambiente Virtual de Aprendizagem - AVA, com a utilização do software GeoGebra.

O que chamou a atenção dos professores para esse projeto foi a expectativa em atenuar a insegurança em ensinar Geometria, aperfeiçoar seus conhecimentos específicos, desenvolver habilidades no uso de novos recursos, principalmente tecnológicos para, consequentemente, melhorar sua prática em sala de aula.

A possibilidade de ampliação da prática didática, a percepção dos professores com relação à importância do ensino da Geometria, principalmente com o uso de tecnologias digitais, no caso o software GeoGebra, possibilitou o entendimento de alguns conceitos desenvolvidos na formação, os quais eles não tinham, total ou parcialmente, ou, embora os tivessem, não conseguiram entendê-los até então.

Com base nos depoimentos, observações e análises realizadas no decorrer de toda a formação, esta pesquisa mostra a viabilidade de sua continuidade, com a adoção de outros modelos de Ensino Híbrido, podendo ser reestruturada para outros professores e outros conteúdos, o que, certamente, trará contribuições significativas.

Recebido em: 02/11/2019

Aprovado em: 08/04/2020 


\section{Referências}

BERGMANN, Jonathan, SAMS, Aaron. SAI - Uma metodologia Ativa de Aprendizagem. LTC, 03/2016. VitalBook file.

BONILLA, M. H. S.; PICANÇO, A de A. Construindo novas educações. In: Nelson De Luca Pretto. (Org.). Tecnologia e novas educações. 1ed. Salvador: EDUFBA, v. 1, p. 216-230. 2005.

BRASIL. Ministério da Educação. Base Nacional Comum Curricular. Brasília, DF: MEC, 2017.

Secretaria de Educação Fundamental. Parâmetros Curriculares Nacionais. Matemática. Brasília: Ministério da Educação, 2001.

Conselho Nacional de Educação. Diretrizes curriculares nacionais para o curso de Pedagogia. Resolução n. 3, aprovada em 21/02/2006.

COLLINS, A. JOSEPH, D, BIELACZYC, K. Design Research: Theoretical and Methodological Issues. Journal of the Learning Sciences. Evanston, p.13-42. 2014.

CURI, E. A Matemática e os professores dos anos iniciais. São Paulo: Musa, 2005.

LIBÂNEO, J.C. Licenciatura em Pedagogia: a ausência dos conteúdos específicos do ensino fundamental. Por uma Política Nacional de Formação de Professores. São Paulo: UNESP, p.73-94, ANEXOS. 2013.

LOPES, L. M.; KLIMICK, C. e CASANOVA, M.A. Relato de uma experiência de Sistema Híbrido no Ensino Fundamental: Projeto Aula ativa. In: Revista Brasileira de Aprendizagem Aberta e a Distância, São Paulo, 2003.

MELLO, G.N. Formação inicial de professores para a educação básica: uma (re) visão radical. Revista Iberoamericana de Educación, n. 25, p. 147-174. 2001.

MISHRA, P. e KOEHLER, M. J. Technological Pedagogical Content Knowledge: A Framework for Teacher Knowledge. Teachers College Record, v. 108, n.6, p. 1017-1054. 2006.

NACARATO, A. M.; MENGALI, B. L. S., PASSOS, C. L. B. A matemática nos anos iniciais do ensino fundamental: tecendo fios do ensinar e do aprender. 2. Ed.; 3. Reimp. - Belo Horizonte: 
Autêntica Editora, 2017 (Coleção Tendências em Educação Matemática)

NACARATO, A. M.; SANTOS, C. A. Aprendizagem em Geometria na educação básica: a fotografia e a escrita na sala de aula. Belo Horizonte: Autêntica, 2014.

PAVANELLO, R. M. O abandono do ensino de Geometria: causas e consequências. Zetetiké. Campinas, SP, Ano I, no 1, p. 7-17, 1993.

PEREZ, G. Pressupostos e reflexões teóricas e metodológicas da pesquisa participante no ensino de Geometria para aas camadas populares. Tese de Doutorado em Educação, Área de Metodologia do Ensino. Campinas - SP. Universidade Estadual de Campinas, 1991.

PIMENTEL, F. S. C. Formação de Professores e Novas Tecnologias: possibilidades e desafios da utilização de webquest e webfólio na formação continuada. 2007. Disponível em: 〈http://www.ensino.eb.br/artigos/artigo_webquest_webfolio.pdf>. Acesso em: 21 mar. 2008.

PONTE, J. P.; BROCARDO, J.; OLIVEIRA, H. Investigações Matemáticas na Sala de Aula. Editora Autêntica, 2009.

RIBEIRO, R. M. O papel da reflexão sobre a prática no contexto da formação continuada de professores de Matemática. Dissertação de Mestrado em Educação Matemática. São Paulo, Pontifícia Universidade Católica - PUC, 2005

SHULMAN, L. S. Knowledge and teaching: foundations of the new reform. Harvard Educational Review, v. 57, n. 1, p. 1-22. 1987.

TORI, R; LITTO, F. M. LITTO; FORMIGA, M. Educação a Distância: O Estado da Arte. ABED - Associação Brasileira de Educação a Distância. São Paulo: Pearson Education do Brasil, 2009. (capítulo 17). 